\title{
The modern firm
}

\author{
Fiona Godlee editor in chief
}

The BMJ

The NHS is in the grip of a workforce crisis. Across England one in 12 posts $(8 \%)$ are now vacant, reports the Nuffield Trust. This is part of a growing global shortage of healthcare workers but has its own special causes and characteristics: failure to train and retain enough home grown health professionals, failure to recruit sufficient numbers from abroad, and an unprecedented wave of trainee departures and early retirement driven by rota gaps, overwork, disillusionment and pension rules.

As Andy Cowper reported a few weeks ago (doi:10.1136/bmj. 12209), despite promises of 5000 extra GPs, we now have fewer GPs per patient for the first time since the 1960s, 40000 nurse vacancies, and $10 \%$ of specialty medical and $32 \%$ of psychiatry training posts unfilled. The result is a vicious cycle of low morale and burnout driving doctors and nurses out of the NHS and deterring others from joining, which in turn puts yet more unsustainable pressure on those who stay.

The scale of the problem has at last hit home with government, say Nigel Edwards and Billy Palmer (doi:10.1136/bmj.14144), and an interim workforce plan, though long overdue, has some sensible suggestions. But new staff and new roles will take years to materialise, and the NHS has a huge task ahead if it is even to retain its current staff, says Edwards.

High on the list of suggestions for happier, more motivated, and safer hospital doctors is the return of "the firm." This is more than dewy eyed nostalgia. The firm is a shorthand for many of the things that the best employers have always known: that for people to flourish in their work they need nurture, support, community, and a sense of belonging, and the assurance that your boss knows who you are, can guide and advise you, and will support you when things go wrong.

Efforts to restore the best elements of the firm are now being actively pursued, reports Abi Rimmer (doi:10.1136/bmj.14105). The Royal College of Surgeons and Health Education England are piloting a modern firm, with longer placements, regular meetings between trainees and supervisors, and better resourced rotas. The Royal College of Physicians is also looking at how modern teams can provide more education and peer support. Both initiatives aim to make junior doctors feel more valued while also recognising the needs of senior doctors: specifically their own need for training and for time to train and support their junior colleagues.

Lack of the right senior support was starkly evident in the case of Hadiza Bawa-Garba (doi:10.1136/bmj.14130). Her treatment in the courts and by the GMC left many juniors fearing that they too might be an honest mistake away from a criminal conviction, says Jenny Vaughan on BMJ Opinion (https://blogs.bmj.com/ bmj/2019/06/06/medical-manslaughter-will-the-findings-of-anindependent-review-be-a-tipping-point-for-change/). She hopes that the GMC's review of medical manslaughter (doi:10.1136/ bmj.14106) will prove to be a tipping point. Among the many challenges facing the NHS if it is to attract and retain enough staff is changing its culture from blame to learning and from top-down performance management to full investment in its people. 